\title{
Immunological investigations in post-traumatic granulomatous and non-granulomatous uveitis
}

\author{
AMJAD RAHI, GWYN MORGAN, IVOR LEVY, AND WILLIAM DINNING \\ From the Department of Pathology, Institute of Ophthalmology, University of London, the London Hospital, \\ and the Royal Free Hospital, London
}

SUMMARY Histopathological and immunological investigations have been performed in 16 cases of post-traumatic granulomatous (10) and non-granulomatous uveitis (6). Most cases of sympathetic ophthalmitis showed evidence of cell mediated immunity to uveoretinal antigens, though it was not possible to make a definitive diagnosis on immunological grounds alone. Three patients with post-traumatic non-granulomatous uveitis showed a positive immunological response to ocular antigens, and 2 of these later developed clinical evidence of sympathetic ophthalmitis, which suggests that post-traumatic non-granulomatous uveitis in such cases may represent a presympathetic (i.e., incipient) or modified stage of the disease.

Perforating wounds of the eye are common and occur particularly in children at play or adults engaged in industry. Road traffic accidents also cause many. These ocular injuries show a wide variation in their clinical and histological behaviour. Thus, from minimal clinical signs and symptoms, the injured eyes may show laceration, disorganisation, purulent infection, prolapse of intraocular contents, chronic endophthalmitis, and phthisis bulbi. Occasionally the inflammation in the injured eye may take a different course, persisting for a long time; later the uninjured contralateral eye may show evidence of irritation and inflammation (i.e., sympathetic ophthalmitis), which may lead to blindness.

Although Hippocrates (459-355 BC) knew that persons who had lost one eye from injury frequently became blind in the other eye, William MacKenzie (1840), a clergyman who became an ophthalmologist, first fully documented this condition of sympathetic involvement of the uninjured eye. Fuchs (1905), however, first clearly described the histological changes in the injured (i.e., exciting) and the uninjured (i.e., sympathising) eyes. The subject was later extensively reviewed by Lowenstein (1945).

It is now generally agreed that in sympathetic ophthalmitis there is typically a diffuse and often massive infiltration of the entire uvea by lymphocytes and eosinophils, with foci of epithelioid cells

Address for reprints: Dr A. H. S. Rahi, Department of Pathology, Institute of Ophthalmology, Judd Street, London WC1H 9QS frequently containing giant cells but without caseation. In the early stages the epithelioid cell nests are either absent or tend to be small (Collins, 1949), but later they increase in size, phagocytose melanin pigment, and merge with the lymphocytic infiltration, the result being a mottled appearance in the uvea (Figs. 1-4). Although the sensory retina is not affected by the infiltrate, isolated nodular lesions of epithelioid cells known as Dálen-Fuchs nodules may occur beneath the pigment epithelium, particularly in the region of the ciliary body and pars plana. A perforating wound, especially with uveal prolapse, is thought to be a constant feature in the exciting eye.

Because of the increased awareness of this complication and the wide usage of antibiotics and corticosteroids the incidence of typical sympathetic ophthalmitis appears to have fallen considerably, though there are still occasional reports of such complications even after sterile wounds such as are made in routine intraocular surgery (Shammas et al., 1977). It is possible, however, that this apparent decrease in incidence may be due to the failure of clinical and histological diagnosis, at least in some unilateral cases, either because of early enucleation before the characteristic histological changes have appeared, or because the tissue response has been substantially modified by better wound repair and possible concomitant steroid therapy.

It has been shown that antigen-antibody aggregates prepared with different concentrations of the 
Fig. 1 The typical mottled appearance in the uvea. The pale areas are foci of histiocytes and the dark areas represent lymphocytes and other inflammatory cells. Haematoxylin and eosin, $\times 340$
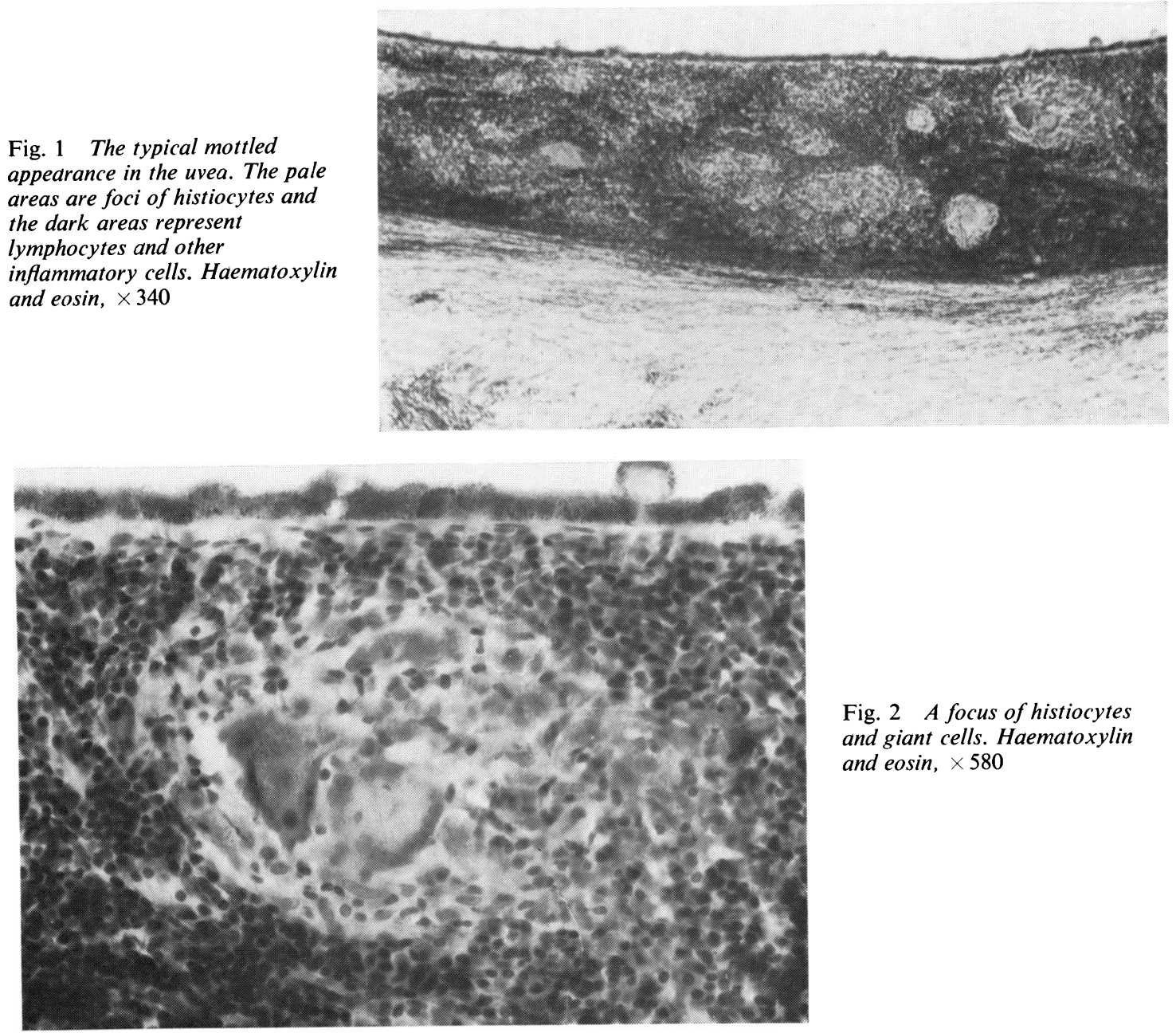

Fig. 2 A focus of histiocytes and giant cells. Haematoxylin and eosin, $\times 580$ same antigen may produce different histological pictures, ranging from a simple leucocytic infiltration to well formed granulomata with typical epithelioid cells and giant cells (Spector and Heesom, 1969), and that the use of corticosteroids may modify or suppress the development of an allergic reaction. By analogy it is possible to expect a variation in the clinical and histological appearances of sympathetic ophthalmitis, which is considered to be an autoimmune disease due to sensitisation with uveoretinal antigens (Elschnig, 1910; Woods, 1921; Verhoeff, 1927; Friedenwald, 1934; Hammer, 1971; Marak, 1976) in which autosensitisation would depend on the nature of the injury-and therefore the amount of antigen released-and on the immune status of the individual.

It would also seem that the term sympathetic ophthalmitis may have a somewhat different con- notation from clinical, histopathological, and immunological points of view. Thus to the clinician's sympathetic ophthalmitis is by definition bilateral uveitis in which inflammation in the injured eye is followed by inflammation in the uninjured eye. From the pathologist's point of view sympathetic ophthalmitis will be diagnosed only if there is the characteristic histological picture described above. If an injured eye shows only non-granulomatous inflammation, therefore, a pathologist will be reluctant to diagnose sympathetic ophthalmitis even if there is a clinical suggestion of some inflammation in the opposite uninjured eye. From the immunological point of view sympathetic ophthalmitis is an autoallergic phenomenon triggered by trauma and perhaps some occult infection in the injured eye, in which process the fellow eye may or may not be involved. Whether it is depends on the dose of 


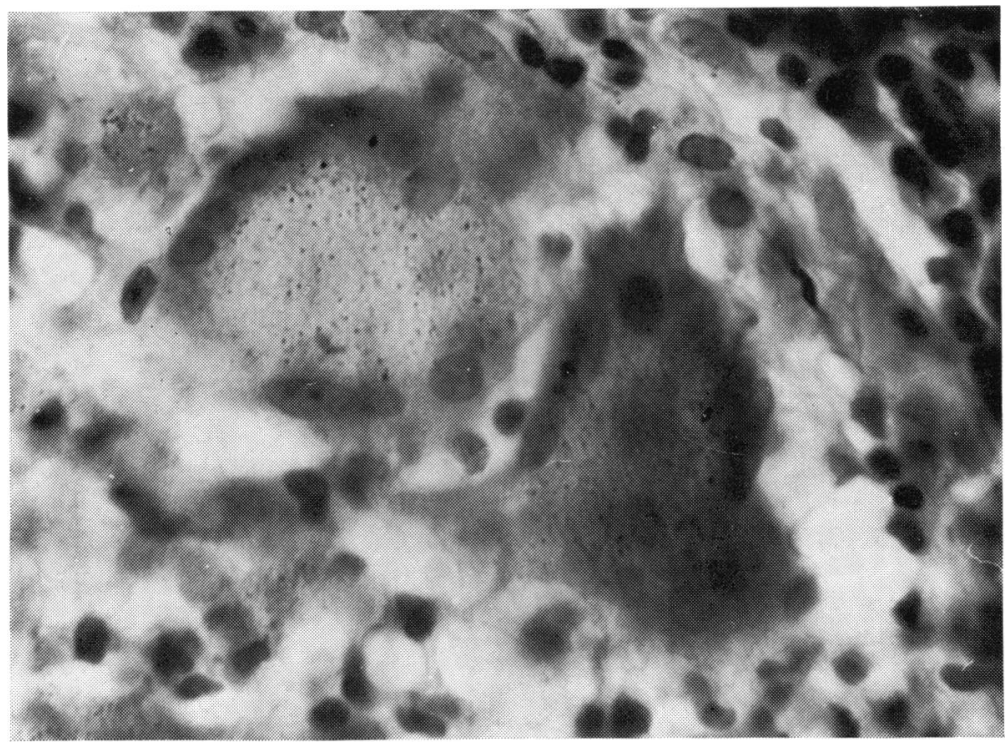

Fig. 3 Two giant cells, containing melanin pigment within their cytoplasm.

Haematoxylin and eosin, $\times 1550$

Fig. 4 Lymphocytic infiltration of the choroid with 3 eosinophils (arrowed). Haematoxylin and eosin, $\times 1550$

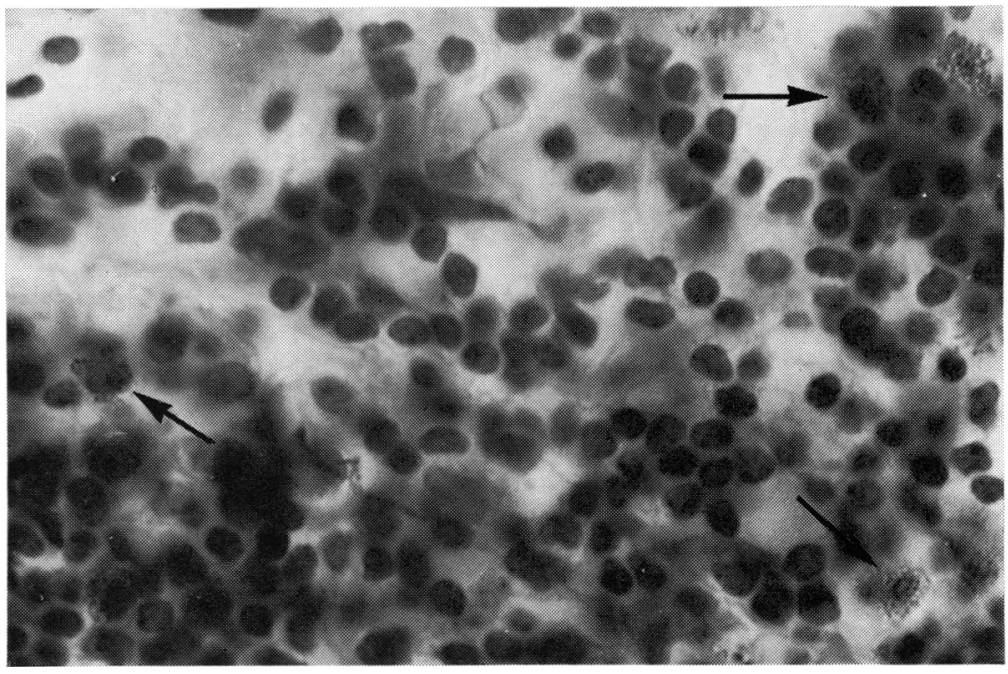

the antigen, the way it is presented to the immunocompetent cells, the immune status of the individual, and whether or not he is being treated with immunosuppressive drugs. So long as these patients show in-vitro evidence of sensitisation to uveoretinal antigens, the immunologist can recognise the incipient or threatening stages of post-traumatic autoallergic uveitis (i.e., sympathetic ophthalmitis) whether the enucleated eye shows uveitis with the diagnostic histological features or not.

The question arises, therefore, whether a diagnosis of sympathetic ophthalmitis (post-traumatic allergic uveitis) can be entertained on the basis of positive immunological tests even if the uninjured eye is clinically normal at the time of investigation and the injured eye shows only the pathological changes of a nondescript inflammation (Fig. 5). The present study was carried out in an attempt to provide an answer to this question.

\section{Methods and materials}

A total of 16 patients were investigated. Fifteen of them had their injured eyes enucleated either because of early involvement of the other eye or because the injured eye was severely inflamed and painful and did not serve any useful purpose. The eyes were examined histologically by the conven- 
Fig. 5 Non-granulomatous uveitis. Haematoxylin and eosin, $\times 620$

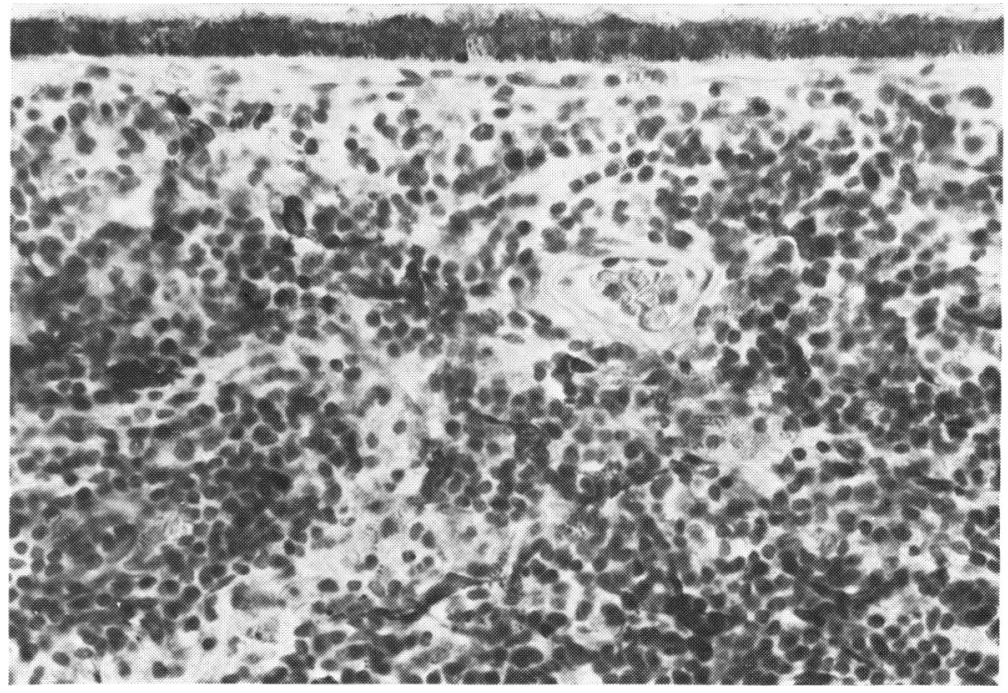

tional techniques (Ashton, 1967). In none of the eyes was there any evidence of lens-induced uveitis.

Blood was collected from these 15 patients either before or a few days after enucleation and examined for the serum concentrations of immunoglobulins $\mathrm{G}, \mathrm{A}$, and $\mathrm{M}$ by the standard radial immunodiffusion technique. Blood was also examined from 1 patient who showed clinical evidence of sympathetic ophthalmitis in the uninjured eye but in whom the histology of the eye was not available because the enucleation of the exciting eye was deferred.

Specimens of blood from 98 healthy adults matched for age and sex were also tested to obtain a normal range for the serum immunoglobulins. The individual values obtained were logarithmically transformed to obtain the mean and the range with $95 \%$ confidence limits. The significance of the differences between the means was tested by Student's $t$ test.

Cryostat sections of a composite block consisting of rat liver, kidney, stomach, diaphragm, and parotid gland were used to detect non-organ-specific autoantibodies such as antinuclear, anti-smoothmuscle, antireticulin, antimitochondrial, and antiskeletal antibodies. A standard indirect immunofluorescent technique and an epifluorescence microscope (Zeiss) with FITC interference filter were used. The results were analysed by the chi-square method.

Delayed hypersensitivity (i.e., cellular immunity) to non-specific mitogens (e.g., phytohaemagglutinin) and to uveoretinal antigens was tested in 16 patients. The technique used was either the leucocyte migration inhibition test or the lymphocyte transformation test (Hammer, 1971, 1974). The antigens used in the present study were crude extracts of human choroid and the adherent retinal pigment epithelium, the sensory retina, and the anterior uvea. The various antigens were prepared as $10 \%$ (wet weight) homogenates in phosphate-buffered saline $(\mathrm{pH}$ $7 \cdot 2$ ), and $0.1 \mathrm{ml}$ samples were used separately in each culture chamber or tube. The tests were duplicated, and a migration inhibition of more than $25 \%$ and a transformation index of over 1.5 were regarded as positive for the present study.

\section{Results}

\section{HISTOPATHOLOGY}

Of the 15 enucleated eyes 5 showed the typical features of granulomatous uveitis with DálenFuchs nodules, and the contralateral eyes showed the clinical features of sympathetic ophthalmitis. In addition to these 5 cases 1 case showed the clinical features of sympathetic ophthalmitis with the ophthalmoscopic changes resembling DálenFuchs spots (i.e., the clinical equivalent of histological nodules) in the exciting eye. This eye was not enucleated.

Ten enucleated eyes showed the histological features of non-granulomatous inflammation, but only in 2 cases did the contralateral eye show clinical evidence of mild inflammation initially, both these cases developing clear clinical signs of sympathetic ophthalmitis at a later date.

SERUM IMMUNOGLOBULINS

The results are summarised in Table 1 and the graph in Fig. 6. The geometric means of IgG and IgA levels were not significantly raised in either group 
Table 1 Serum immunoglobulins in post-traumatic uveitis

\begin{tabular}{lllll}
\hline $\begin{array}{l}\text { Presenting } \\
\text { diagnosis }\end{array}$ & $\begin{array}{l}\text { Number } \\
\text { of } \\
\text { cases }\end{array}$ & $\begin{array}{l}\text { IgG IU/ml } \\
\text { Mean } \\
\text { (Range) }\end{array}$ & $\begin{array}{l}\text { IgA IU/ml } \\
\text { Mean } \\
\text { (Range) }\end{array}$ & $\begin{array}{l}\text { IgM IU/ml } \\
\text { Mean } \\
\text { (Range) }\end{array}$ \\
\hline Healthy adults & 98 & $\begin{array}{l}121 \\
(68-217)\end{array}$ & $\begin{array}{l}125 \\
(55-286)\end{array}$ & $\begin{array}{l}151 \\
(68-333)\end{array}$ \\
$\begin{array}{c}\text { Granulomatous } \\
\text { uveitis } \\
\text { (sympathetic } \\
\text { ophthalmitis) }\end{array}$ & $6 *$ & $\begin{array}{l}122 \\
(80-210)\end{array}$ & $\begin{array}{l}137 \\
(99-210)\end{array}$ & $239 \ddagger$ \\
$\begin{array}{c}\text { Non-granuloma- } \\
\text { tous uveitis }\end{array}$ & $10 \dagger$ & $\begin{array}{l}137 \\
(100-178)\end{array}$ & $\begin{array}{l}161 \\
(99-312)\end{array}$ & $\begin{array}{l}256 \S \\
(140-480)\end{array}$ \\
\hline
\end{tabular}

*One case diagnosed clinically but not histopathologically

†Two cases developed clinical evidence of sympathetic ophthalmitis at a later date

$\ddagger \mathbf{P}<0.01$

$\S \mathrm{P}<0.001$

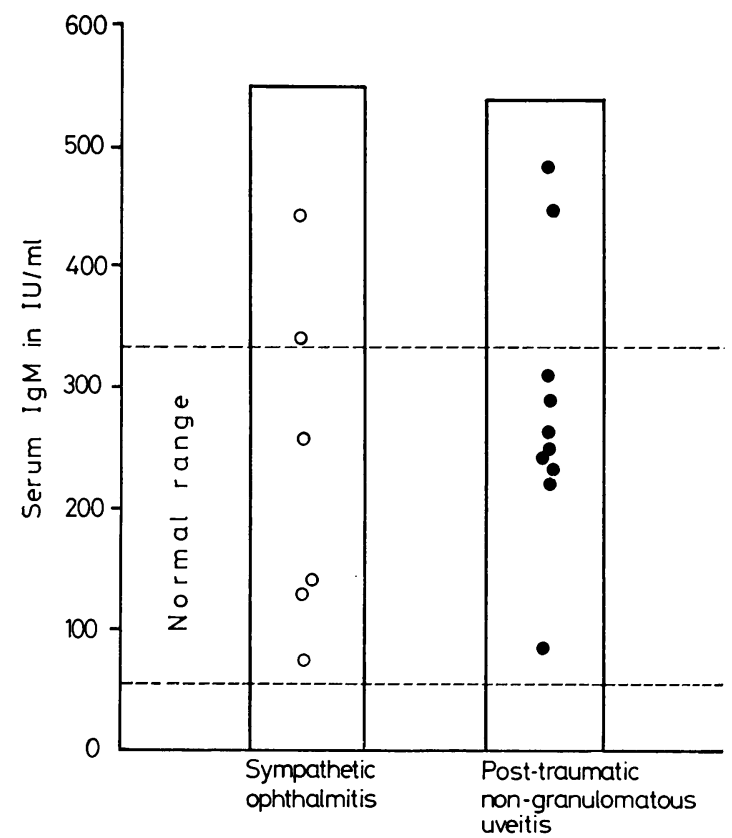

Fig. 6 Serum immunoglobulin $M$ in post-traumatic granulomatous and non-granulomatous uveitis

of cases. Though the geometric mean concentration of IgM was raised in both groups, it will nevertheless be seen from the graph that only 2 cases each of sympathetic ophthalmitis and non-granulomatous uveitis showed levels which were above the upper limit of the normal range.

NON-ORGAN-SPECIFIC AUTOANTIBODIES

Smooth muscle antibodies in low titres $(1 / 10)$ were present in the serum of 2 cases of sympathetic ophthalmitis and in 3 cases of non-granulomatous uveitis. Antinuclear antibodies were found in only 1 case of sympathetic ophthalmitis. The incidence of these non-organ-specific autoantibodies was statistically insignificant.

\section{CELL MEDIATED IMMUNITY}

The results are summarised in Table 2. Of the 6 cases of sympathetic ophthalmitis (5 histologically proved and 1 diagnosed clinically) 3, including the case diagnosed clinically, showed evidence of delayed tissue allergy to uveoretinal antigens (i.e., choroid + pigment epithelium). One case reacted against sensory retinal antigen and another against anterior uveal extract. The test was negative in 1 case in spite of both histological and clinical evidence of sympathetic ophthalmitis.

On the contrary, 7 of the 10 cases of post-traumatic non-granulomatous uveitis showed no evidence of delayed tissue allergy to uveoretinal antigens. In 2 of the 3 other cases with a positive lymphocyte transformation test, however, clinical evidence of sympathetic ophthalmitis developed several weeks later.

The response to non-specific mitogens (phytohaemagglutinin) was normal.

\section{Discussion}

It would appear that in a fully developed case of sympathetic ophthalmitis the enucleated eye generally shows features of granulomatous panuveitis with well developed Dálen-Fuchs nodules. Occasionally, however, if the duration of onset is short and enucleation is performed at the first suspicion of sympathetic ophthalmitis (as happened in 1 of our cases) the eye may not show granulomatous

Table 2 Cell-mediated immunity in post-traumatic uveitis (lymphocyte transformation and leucocyte migration inhibition tests)

\begin{tabular}{|c|c|c|c|c|c|}
\hline \multirow[t]{2}{*}{$\begin{array}{l}\text { Presenting } \\
\text { diagnosis }\end{array}$} & \multirow{2}{*}{$\begin{array}{l}\text { Number } \\
\text { of } \\
\text { cases }\end{array}$} & \multicolumn{3}{|c|}{ Number positive } & \multirow[t]{2}{*}{$\begin{array}{l}\text { Number } \\
\text { negative }\end{array}$} \\
\hline & & $\begin{array}{l}\text { Choroid and } \\
\text { retinal } \\
\text { pigment } \\
\text { epithelium }\end{array}$ & $\begin{array}{l}\text { Sensory } \\
\text { retina }\end{array}$ & $\begin{array}{l}\text { Anterior } \\
\text { uvea }\end{array}$ & \\
\hline $\begin{array}{l}\text { Granulomatous } \\
\text { uveitis } \\
\text { (sympathetic } \\
\text { ophthalmitis) }\end{array}$ & 6 & $3 *$ & 1 & 1 & 1 \\
\hline $\begin{array}{l}\text { Non-granulo- } \\
\text { matous } \\
\text { uveitis }\end{array}$ & 10 & $3 \uparrow$ & - & - & 7 \\
\hline
\end{tabular}

* One case diagnosed clinically but not histopathologically

†Two cases developed clinical evidence of sympathetic ophthalmitis at a later date 
lesions (Greaves, 1948), either because there has been insufficient time for this reaction to develop or the immune response of the host was not congenial, or because the physicochemical nature of the antigen-antibody aggregate was such that it did not stimulate a granulomatous reaction (Spector and Heesom, 1969). In such doubtful cases immunological investigations concerning cellular immunity to uveoretinal antigens may be diagnostically helpful, although, as is evident from this study, these tests may be negative in a proportion of histologically proved cases of sympathetic ophthalmitis (see Table 2).

In the past it has been argued that the offending antigen in sympathetic ophthalmitis is the uveal pigment. The present study has demonstrated, however, that patients may show evidence of hypersensitivity to other antigens such as those residing in the photoreceptors and the pigment epithelium of the retina (Rahi, 1970; Reich et al., 1974). Thus it provides further evidence to support the recognised view that sympathetic ophthalmitis is an autoimmune disease (Collins, 1949) involving both uveal and retinal antigens (Wong et al., 1971; Marak et al., 1971; Marak et al., 1973).

The significance of a raised IgM in some cases of post-traumatic non-granulomatous uveitis is not known. Woods (1921), using bovine uvea as antigen, detected complement-fixing antibodies in those cases of post-traumatic uveitis which ultimately did not progress to classical sympathetic ophthalmitis. It is of interest that IgM is a complement-fixing antibody which, as suggested by Woods, may have a protective role, and this phenomenon may be analogous to immune enhancement in malignant tumours. This may not be true, however, in every case, because some of the patients with sympathetic ophthalmitis also had raised levels of IgM.

It is possible on the other hand that post-traumatic non-granulomatous uveitis represents a 'forme fruste' or an early stage of sympathetic ophthalmitis or allergic uveitis which, due to some unknown cause, remains limited to the injured eye. In some cases, as time progresses and the patients develop cellular hypersensitivity, the reaction becomes granulomatous and the other eye becomes involved. Thus the appearance of delayed tissue allergy to uveoretinal antigens after a penetrating wound of the eye in an otherwise healthy person may signify ocular hypersensitivity, and a well controlled study with a long follow-up could ultimately decide whether or not such individuals should be treated with immunosuppressive drugs at least during the period when the disease in the injured eye is active.

It has been suggested that sympathetic ophthal- mitis may begin as 'traumatic uveitis serosa', possibly due to invasion by a virus (Sie-Boen-Lian, 1963) or to mycoplasma (Schrek, 1975), which may progress due to autosensitisation and involve the other eye to produce the histological changes typical of sympathetic ophthalmitis. In these cases raised IgM levels may represent an immune response to an occult or a subclinical intraocular infection. It may be of help, therefore, if all patients with perforating wounds have their immunological profile, in particular their cellular immune responses, investigated at reasonably frequent intervals until the inflammation subsides, so that corticosteroids and other immunosuppressive drugs may be given in sufficient doses at a time when they are most likely to be beneficial.

There was no increased incidence of non-organspecific autoantibodies in sympathetic ophthalmitis, and the response to phytohaemagglutinin was normal. This supports the view that the $\mathrm{T}$ lymphocyte population is normal in this disease (Boone et al., 1976), though the 'null' lymphocytes (i.e., lymphocytes which are neither B nor T) may be increased in some patients.

It was stated in the introduction to this paper that the purpose of the investigations was to see whether or not a diagnosis of sympathetic ophthalmitis can be made on the basis of positive immunological tests even if the uninjured eye is clinically normal at the time of investigation and the injured eye shows only the pathological changes of nongranulomatous inflammation. Since some cases of both sympathetic ophthalmitis and simple posttraumatic non-granulomatous uveitis showed raised IgM levels, this immunological criterion does not appear to have a diagnostic significance. On the other hand 5 of 6 cases of sympathetic ophthalmitis showed evidence of cell-mediated hypersensitivity to uveoretinal antigens, though 1 case which was confirmed histopathologically showed no evidence of a positive reaction, in spite of the fact that the immunological response had not been suppressed by steroid therapy. Seven of the 10 cases of post-traumatic non-granulomatous uveitis did not show positive cell-mediated immunological responses, though 2 of the 3 other cases with positive responses later developed clinical evidence of sympathetic ophthalmitis.

It is clear from these results that the cell-mediated immunological response to ocular antigens in both typical and atypical cases of sympathetic ophthalmitis is often positive, although it may sometimes be negative. Occasionally, however, some patients may never develop sympathetic ophthalmitis even in the presence of a positive cell-mediated hypersensitivity to uveoretinal antigen. It is not possible, 
therefore, to make a definitive diagnosis of sympathetic ophthalmitis on immunological grounds alone.

We are grateful to Professor N. H. Ashton for his help and criticism. We also thank the ophthalmic surgeons for supplying the blood samples, Mr V. J. Elwood and Mr J. Prasad for technical assistance, and Mrs A. Wood for typing the paper.

\section{References}

Ashton, N. (1967). Techniques for the histological examination of the eye. Association of Clinical Pathologists Broad Sheet No. 59. BMA: London.

Boone, W. B., Gupta, S., Hanson, J., and Good, R. A. (1976). Lymphocyte subpopulation in patients with sympathetic ophthalmitis and non-granulomatous uveitis. Investigative Ophthalmology, 15, 957-961.

Collins, R. C. (1949). Experimental studies on sympathetic ophthalmia. American Journal of Ophthalmology, 32, 1687-1699.

Elschnig, A. (1910). Studien zur sympathischen Ophthalmie. Albrecht von Graefes Archiv für Ophthalmologie, 76, 509-546.

Friedenwald, J. S. (1934). Notes on allergy theory of sympathetic ophthalmia. American Journal of Ophthalmology, 17, 1008-1018.

Fuchs, E. (1905). Uber sympathisierende Entzündung. Albrecht von Graefes Archiv für Ophthalmologie, 61, 365456.

Greaves, A. (1948). A contribution to the microscopical anatomy of the sympathizing eye. British Journal of Ophthalmology, 32, 545-550.

Hammer, H. (1971). Lymphocyte transformation test in sympathetic ophthalmitis and the Vogt-Koyanagi-Harada syndrome. British Journal of Ophthalmology, 55, 850-852.

Hammer, H. (1974). Cellular hypersensitivity to uveal pigment confirmed by leucocyte migration tests in sympathetic ophthalmitis and the Vogt-Koyanagi-Harada syndrome. British Journal of Ophthalmology, 58, 773-776.

Hippocrates (459-355 BC). Quoted by Samuels, B., and
Fuchs, A. (1952). Clinical Pathology of the Eye,pp. 148-164. Cassell: Toronto.

Lowenstein, A., (1945). The sympathizing eye. Transactions of the Ophthalmological Societies of the United Kingdom, 65, 219-231.

Mackenzie, W. (1840). A Practical Treatise on the Diseases of the Eye, 3rd edn., pp. 523-534. Longman: London.

Marak, G. E. (1976). Immunopathology of sympathetic ophthalmia. Modern Problems in Ophthalmology, 16, 102105.

Marak, G. E., Aye, M. S., and Alepa, F. B. (1973). Cellular hypersensitivity in penetrating eye injuries. Investigative Ophthalmology, 12, 380-382.

Marak, G. E., Font, R. L., Johnson, M. C., and Alepa, F. P. (1971). Lymphocyte-stimulating activity of ocular tissues in sympathetic ophthalmia. Investigative Ophthalmology, 10, 770-774.

Rahi, A. H. S. (1970). Autoimmunity and the retina. British Journal of Ophthalmology, 54, 441-444.

Reich D'Almeida, F., and Rahi, A. H. S. (1974). Antigenic specificity of retinal pigment epithelium and non-immunological involvement in retinal dystrophy. Nature, 252, 307-308.

Schrek, E. (1975). Further investigations for the demonstration of a specific microorganism in sympathetic ophthalmia. Albrecht von Graefes Archiv für klinische und experimentelle Ophthalmologie, 193, 229-243.

Shammas, H. F., Zubyk, N. A., and Stanfield, T. F. (1977). Sympathetic uveitis following glaucoma surgery. Archives of Ophthalmology, 95, 638-641.

Sie-Boen-Lian (1963). Cultivation of virus in a case of sympathetic ophthalmia. Ophthalmologica, 146, 43-47.

Spector, W. G., and Heesom, N. (1969). The production of granulomata by antigen-antibody complexes. Journal of Pathology, 98, 37-39.

Verhoeff, F. H. (1927). An effective treatment for sympathetic uveitis. Archives of Ophthalmology, 56, 28-41.

Wong, V. G., Anderson, R., and O'Brien, P. J. (1971). Sympathetic ophthalmia and lymphocyte transformation. American Journal of Ophthalmology, 72, 960-968.

Woods, A. C. (1921). Immune reactions following injuries to the uveal tract. Journal of the American Medical Association, 77, 1317-1322. 